\title{
PENGEMBANGAN MEDIA PEMBELAJARAN MENGGUNAKAN GEOGEBRA PADA SUB POKOK BAHASAN GARIS SINGGUNG PERSEKUTUAN DUA LINGKARAN
}

\author{
Elok Rohmawati*, Vigih Hery Kristanto \\ Program Studi Pendidikan Matematika, Universitas Katolik Widya Mandala Madiun; \\ Jl. Manggis, 15-17, Madiun, Jawa timur, (0351) 453328

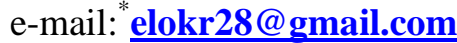

\begin{abstract}
Abstrak. Penelitian ini merupakan penelitian pengembangan yang bertujuan untuk untuk mengetahui proses dan hasil pengembangan media pembelajaran matematika menggunakan Geogebra pada sub pokok bahasan garis singgung persekutuan dua lingkaran. Perangkat pendukung yang digunakan adalah RPP, BKS, BPG, dan THB. Tahapan pengembangan yang dipilih yaitu Metode Research and Development (R\&D) yang telah dimodifikasi dengan menambahkan kriteria Nieveen yaitu valid, praktis dan efektif. Teknik pengumpulan data menggunakan angket, lembar observasi dan tes. Menurut kriteria kepraktisan, diketahui angket kemudahan menggunakan media mencapai $79,8 \%$. Pengoperasian media ini sangat mudah sehingga cara menggunakannya mudah diingat dan dapat digunakan sebagai alat bantu untuk mempelajari materi. Angket keminimalan peran guru mencapai $81 \%$. Dengan menggunakan media aktivitas guru dalam menjelaskan materi menjadi sedikit, karena siswa lebih banyak mengamati, menyimpulkan pendapat, dan mengerjakan soal, sehingga interaksi guru dengan siswa sedikit, dan penjelasan materi cukup menggunakan media. Lembar observasi keminimalan peran guru sebesar 76,95\%. Dari pengamatan observer siswa lebih banyak mengamati, tidak mengalami kesulitan dalam penggunaan media. Namun, pembelajaran tidak dapat selesai seperti di RPP. Menurut kriteria keefektifan yang dilihat dari tes hasil belajar siswa sehingga ketuntasan secara klasikal mencapai 35\%. Hal ini dikarenakan pembelajaran terlalu fokus pada pengamatan dan penemuan rumus sehingga siswa kurang berlatih dalam mengerjakan soal. Dari penelitian ini diperoleh beberapa hasil temuan, yaitu: media pembelajaran menggunakan Geogebra, perangkat pendukung RPP, BKS, BPG, THB, dan instrumen mempunyai tingkat validitas pada kriteria sangat valid, media pembelajaran menggunakan Geogebra mudah digunakan, media pembelajaran menggunakan Geogebra dengan perangkat pendukung dapat meminimalkan peran guru sehingga media memenuhi kriteria praktis. Tes hasil belajar belum tuntas secara klasikal karena ketuntasan secara klasikal tidak mencapai $75 \%$ ke atas, artinya media belum memenuhi kriteria efektif.
\end{abstract}

Kata Kunci: Media Pembelajaran, Geogebra, Garis Singgung Persekutuan, Matematika

Abstract. This research is a development research that aims to to find out the process and result of development of learning media of mathematics using Geogebra on sub subject of tangent alliance of two circles. Supporting devices used are RPP, BKS, BPG, and THB. The chosen development stage is Research and Development (R \& D) which has been modified by adding Nieveen criteria that is valid, practical and effective. Data collection techniques used questionnaires, observation sheets and tests. According to the criteria of practicality, it is known that the questionnaire of ease of using media reaches $79.8 \%$. The operation of this media is so easy that it's easy to remember and can be used as a tool to learn the material. Questionnaires the role of teachers reached $81 \%$. By using the teacher's activity media in explaining the material to be a little, because the students are more observing, summing up opinions, and working on the problem, so the teacher's interaction with the students is minimal, and the material explanation is enough to use the media. Observation sheet minimizes teacher's role by $76.95 \%$. From the observer observation the students observed more, no difficulties in the use of media. However, learning cannot be finished as in RPP. According to the effectiveness criteria seen from the test of student learning outcomes so that the mastery of classical reach $35 \%$. This is because learning is too focused on observation and discovery of the formula so that students do not practice in doing the problem. From this research, there are several findings, namely: learning 
media using Geogebra, supporting tool, namely RPP, BKS, BPG, THB and instrument have validity level on valid criteria, learning media using Geogebra is easy to use, learning media using Geogebra with supporting device can minimize the role of teachers so that the media meet the practical criteria. The test of learning outcomes has not been completed in a classical manner because the classical completeness does not reach $75 \%$ upwards, meaning that the media has not met the effective criteria.

Keyword: learning media, geogebra, guild tangent line, mathematics

\section{Pendahuluan}

Salah satu materi mata pelajaran matematika dalam kurikulum KTSP 2006 untuk kelas VIII SMP adalah garis singgung persekutuan dua lingkaran. Materi ini masuk pada materi pokok geometri. Sehingga untuk dapat memahami materi ini terdapat dua faktor yang paling menentukan, yaitu ada wujud nyata bendanya, bisa dalam bentuk gambar, dengan kata lain, untuk memahami materi ini wajib menggunakan media pembelajaran, dan penguasaan konsep matematika yang dimiliki oleh guru. Kegunaan dari materi ini adalah untuk menyelesaikan berbagai permasalahan di kehidupan sehari-hari yang melibatkan garis singgung lingkaran, misalnya menentukan panjang rantai sepeda yang melingkar pada gir. Tentu karena bermanfaat dalam kehidupan sehari-hari, maka pemahaman konsep siswa terhadap materi ini penting.

Menurut guru matematika SMPN 12 Madiun siswa masih mengalami kesulitan di materi garis singgung persekutuan dua lingkaran. Selain itu, nilai rata-rata ulangan harian dua kelas saat PPL pada bab sebelumnya berturut-turut 53 dan 43. Sebagian besar kesulitan yang dialami oleh siswa di kelas tersebut lupa materi prasyarat, yaitu tentang teorema pytaghoras serta belum dapat membedakan antara garis singgung persekutuan luar dan garis singgung persekutuan dalam. Akibatnya siswa merasa kesulitan ketika menyelesaikan soal latihan. Selain itu, kendala lain yang dialami oleh guru adalah, harus menggambar manual menggunakan penggaris dan jangka pada saat menyajikan materi dan soal latihan tentang garis singgung lingkaran. Proses menggambar ini cukup memakan waktu. Pada saat guru menggambar, siswa banyak yang melakukan kegiatan yang tidak relevan dengan pembelajaran. Misalnya, berbicara dengan teman sebangku sehingga membuat kondisi kelas menjadi gaduh.

Kondisi tersebut mendukung pendapat yang diajukan oleh peneliti, yaitu wajib digunakan media pembelajaran pada saat pelaksanaan proses pembelajaran di kelas. Media pembelajaran menurut Rosyada, adalah segala sesuatu yang dapat menyampaikan dan menyalurkan pesan dari sumber secara terencana sehingga tercipta lingkungan belajar yang kondusif di mana penerimanya dapat melakukan proses belajar secara efisien dan efektif (Dada, 2008). Selain itu, Rusman menyatakan bahwa penggunaan media pembelajaran mendatangkan banyak manfaat, yaitu pembelajaran akan lebih menarik perhatian siswa sehingga dapat menumbuhkan motivasi belajar, materi pembelajaran akan lebih jelas maknanya sehingga dapat lebih dipahami oleh para siswa dan memungkinkan siswa menguasai tujuan pembelajaran lebih baik, metode pembelajaran akan lebih bervariasi, tidak semata-mata komunikasi verbal melalui penuturan kata-kata oleh guru, sehingga siswa tidak bosan dan guru tidak kehabisan tenaga, Siswa lebih banyak melakukan kegiatan belajar, sebab tidak hanya mendengarkan uraian guru, tetapi juga aktivitas lain seperti mengamati, melakukan, mendemonstrasikan dan lain-lain (Rusman, 2012). 
Media pembelajaran memiliki banyak jenis. Di era sekarang, media pembelajaran berbasis komputer (software) sangat digemari. Terdapat beberapa keuntungan menggunakan media pembelajaran berbasis komputer menurut Hannafin dan Peck (Kristanto, 2011), yaitu memungkinkan terjadinya interaksi langsung antara peserta didik dengan materi pelajaran, proses belajar dapat berlangsung secara individual sesuai dengan kemampuan belajar peserta didik, mampu menampilkan unsur audio visual untuk meningkatkan minat belajar (multimedia), dapat memberikan umpan balik terhadap respon siswa dengan segera. Salah satu software yang dapat digunakan untuk melaksanakan proses pembelajaran matematika adalah Geogebra. Menurut Hohenwater dan Fuchs, Geogebra memiliki beberapa manfaat jika digunakan sebagai media pembelajaran, yaitu dapat digunakan untuk demonstrasi dan visualisasi konsep-konsep matematika, sehingga tingkat keabstrakan matematika dapat berkurang, dapat digunakan sebagai alat bantu konstruksi, sehingga dapat digunakan untuk visualisasi dari konstruksi konsep matematika tertentu, dapat digunakan sebagai alat bantu penemuan, sehingga siswa dapat menggunakan Geogebra untuk membantu menemukan konsep matematika tertentu (Hohenwater \& Fuchs, 2017).

Penggunaan Geogebra untuk menunjang proses pembelajaran matematika telah banyak dilakukan. Penerapan Geogebra telah dilakukan pada banyak konsep matematika. Berdasarkan hasil penelitian Iin Nur Indahsari, penggunaan Geogebra untuk perancangan perangkat pembelajaran matematika pada sub pokok bahasan nilai-nilai stasioner untuk kelas IX IPA menghasilkan perangkat pembelajaran yang valid dan praktis, meskipun belum efektif (Indahsari, 2013). Menurut hasil penelitian tersebut, kriteria praktis dipenuhi berdasarkan hasil nilai kemampuan guru dalam mengelola pembelajaran. Hal ini mengindikasikan bahwa penggunaan Geogebra memungkinkan guru dapat mengelola pembelajaran matematika dengan baik. Selain itu, kriteria praktis juga diperoleh berdasarkan keaktifan siswa dan guru selama proses pembelajaran. Berdasarkan hasil penelitian diperoleh bahwa siswa dan guru masuk pada kriteria cukup aktif. Tentunya aktifitas ini adalah aktifitas yang relevan dengan proses pembelajaran.

Dengan demikian, ada kemungkinan penggunaan Geogebra dalam penyajian materi garis singgung lingkaran dapat mengurangi kesulitan siswa dalam mempelajari materi tersebut dan dapat membantu guru untuk dapat menyajikan materi tersebut dengan baik. Berdasarkan uraian di atas, maka dapat dirumuskan permasalahan dalam penelitian ini, yaitu bagaimana proses dan hasil pengembangan media pembelajaran matematika menggunakan Geogebra pada sub pokok bahasan Garis Singgung Persekutuan Dua Lingkaran? Tujuan yang ingin dicapai dalam pengembangan ini adalah untuk mengetahui proses dan hasil pengembangan media pembelajaran matematika menggunakan Geogebra pada sub pokok bahasan Garis Singgung Persekutuan Dua Lingkaran. Produk yang dihasilkan pada pengembangan ini berupa file Geogebra sebagai media pembelajaran matematika pada sub pokok bahasan garis singgung persekutuan dua lingkaran. Selain itu, terdapat produk-produk lain yang mendukung media pembelajaran, yaitu: Rencana Pelaksanaan Pembelajaran (RPP), Buku Petunjuk Guru (BPG), Buku Kerja Siswa (BKS), dan Tes Hasil Belajar (THB). 


\section{Metode Penelitian}

Jenis penelitian ini adalah penelitian dan pengembangan. Menurut Sugiyono, metode penelitian dan pengembangan adalah metode penelitian yang digunakan untuk menghasilkan produk tertentu, dan menguji keefektifan produk tersebut (Sugiyono, 2010). Langkah-langkah pengembangan yang digunakan dalam penelitian ini mengacu pada pendapat Sugiyono, yaitu dimulai dari potensi dan masalah, pengumpulan data, desain produk, validasi desain, revisi desain, uji coba produk, revisi produk, uji coba pemakaian, revisi produk, dan produksi masal (Sugiyono, 2010). Langkah-langkah tersebut tidak dilaksanakan sepenuhnya, karena penelitian ini adalah penelitian dalam skala kecil. Oleh sebab itu, peneliti memodifikasi langkah-langkah penelitian menurut Sugiyono tersebut. Pemodifikasian dilakukan dengan cara menggabungkan langkah validasi desain dan uji coba produk dengan kriteria Nieveen, kemudian langkah uji coba pemakaian, revisi produk, dan produksi masal tidak dilaksanakan.

Nieveen (Tjeerd \& Nienke, 2010) mengemukakan tiga kriteria untuk menentukan kualitas kurikulum (termasuk media pembelajaran) yaitu validitas, kepraktisan dan keefektifan. Kriteria tersebut dapat dilihat pada tabel 1.

Tabel 1. Criteria for high quality interventions Nieveen

\begin{tabular}{|c|c|}
\hline \multicolumn{2}{|l|}{ Criterion } \\
\hline $\begin{array}{l}\text { Relevance (also referred to as content } \\
\text { validity) }\end{array}$ & $\begin{array}{l}\text { there is a need for the intervention and its design } \\
\text { is based on state-of-the-art (scientific) knowledge }\end{array}$ \\
\hline $\begin{array}{l}\text { Consistency (also referred to as } \\
\text { construct validity) }\end{array}$ & the intervention is 'logically' designed \\
\hline Practicality & $\begin{array}{l}\text { the intervention is realistically usable in the } \\
\text { settings for which it has been designed and } \\
\text { developed }\end{array}$ \\
\hline Effectiveness & Using the intervention results in desired outcomes \\
\hline
\end{tabular}

Sumber: (Tjeerd \& Nienke, 2010)

Dengan demikian, hasil modifikasi tahap-tahap pengembangan dalam penelitian ini dapat dilihat pada gambar 1 .

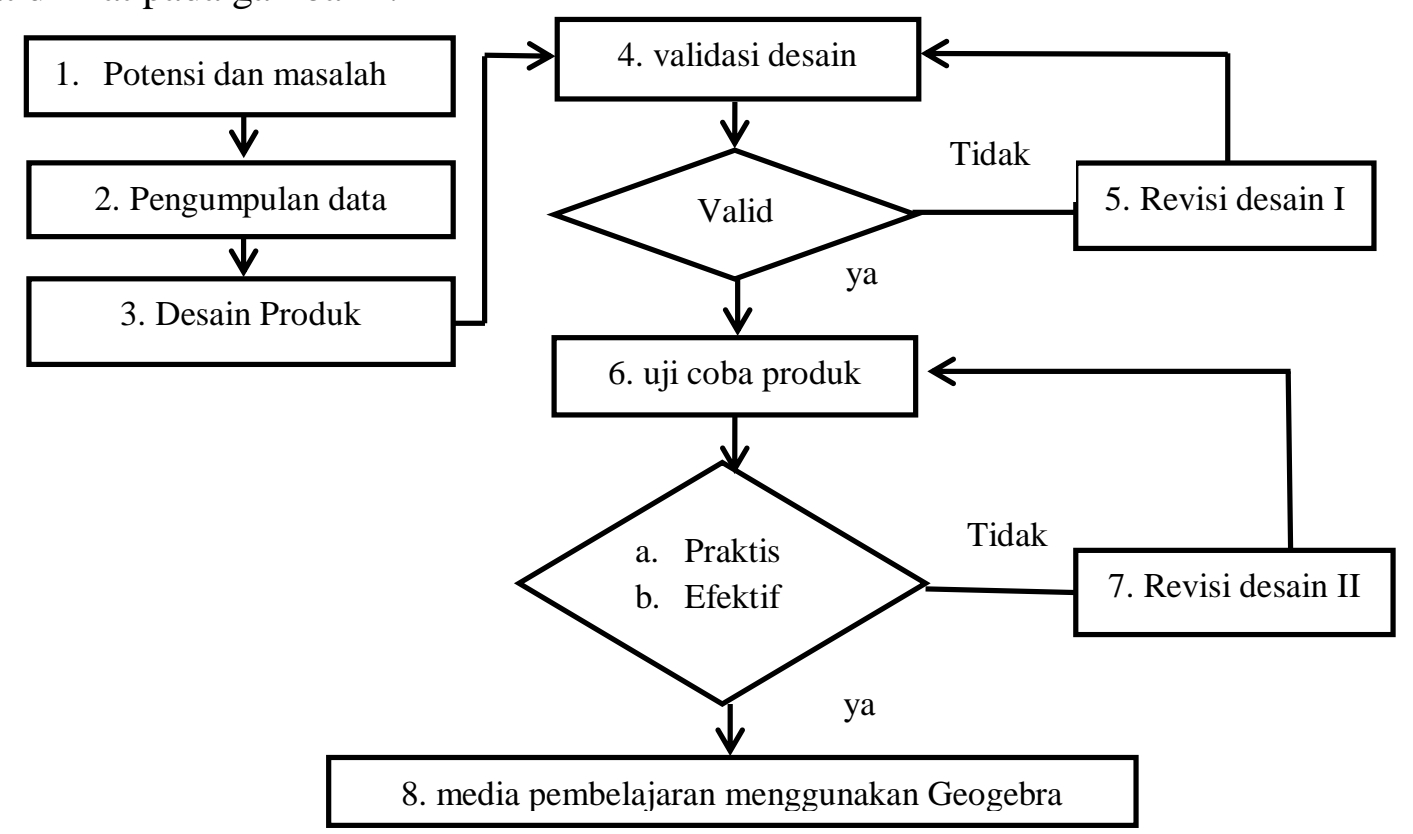

Gambar 1. Modifikasi Langkah-langkah Pengembangan 
Berdasarkan langkah-langkah pengembangan tersebut, instrumen untuk mengukur kevalidan yaitu lembar validasi, instrumen untuk mengukur kepraktisan adalah angket kemudahan menggunakan media Geogebra, angket keminimalan peran guru, dan lembar observasi keminimalan peran guru. Angket dan Lembar observasi keminimalan peran guru digunakan untuk mengukur kepraktisan dikarenakan semakin minimal peran guru dengan adanya media pembelajaran, maka media pembelajaran membuat proses pembelajaran menjadi lebih praktis. Instrumen untuk mengukur keefektifan yaitu dengan tes hasil belajar. Media pembelajaran dan perangkat pendukung akan dinilai validitasnya menggunakan lembar validasi. Setiap pernyataan dalam Lembar Validasi memiliki skor yang dapat dipilih sesuai penilaian ahli. Skor tersebut mulai dari 1 sampai 4. Pernyataan yang validitasnya baik yang mendapatkan skor paling tinggi yaitu 4. Hasil dari proses validasi akan diolah dengan rumus berikut:

$$
P_{i}=\frac{\sum x}{\sum x_{i}} \times 100 \%
$$

$P_{i}$ adalah persentase setiap aspek yang dinilai, $\sum x$ jumlah jawaban responden. dan $\sum x_{i}$ adalah jumlah skor ideal. Kemudian hasil rata-rata Pi dibanding dengan kriteria pada tabel 2.

Tabel 2. Kriteria validasi

\begin{tabular}{|c|c|c|}
\hline Nilai & Kualifikasi & Keterangan \\
\hline $80 \%<\boldsymbol{P}_{\boldsymbol{i}} \leq 100 \%$ & Sangat valid & $\begin{array}{l}\text { Produk siap dimanfaatkan di lapangan untuk } \\
\text { kegiatan pembelajaran }\end{array}$ \\
\hline $60 \%<\boldsymbol{P}_{\boldsymbol{i}} \leq 80 \%$ & Valid & $\begin{array}{l}\text { Produk dapat dilanjutkan dengan menambahkan } \\
\text { sesuatu yang kurang, melakukan pertimbangan- } \\
\text { pertimbangan tertentu, penambahan yang dilakukan } \\
\text { tidak terlalu besar dan tidak mendasar. Produk yang } \\
\text { mencapai nilai ini tidak perlu melewati proses } \\
\text { validasi lagi. }\end{array}$ \\
\hline $40 \%<\boldsymbol{P}_{\boldsymbol{i}} \leq 60 \%$ & Cukup valid & $\begin{array}{l}\text { Pada nilai ini produk memerlukan revisi dengan } \\
\text { meneliti kembali secara seksama dan mencari } \\
\text { kelemahan-kelemahan } c \text { produk } \\
\text { disempurnakan dan harus divalidasi lagi oleh ahli. }\end{array}$ \\
\hline $20 \%<\boldsymbol{P}_{\boldsymbol{i}} \leq 40 \%$ & Kurang valid & $\begin{array}{l}\text { Produk memerlukan revisi yang banyak dan harus } \\
\text { divalidasi lagi oleh ahli. }\end{array}$ \\
\hline $0 \% \leq \boldsymbol{P}_{\boldsymbol{i}} \leq 20 \%$ & Tidak valid & $\begin{array}{l}\text { Merevisi secara besar-besaran dan harus divalidasi } \\
\text { lagi oleh ahli. }\end{array}$ \\
\hline
\end{tabular}

Adapatasi dari (Arifin, 2012).

Setiap pernyataan dalam angket kemudahan menggunakan media Geogebra dan angket keminimalan peran guru diikuti oleh empat pilihan jawaban, yaitu 4 artinya sangat setuju, 3 artinya setuju, 2 artinya tidak setuju, dan 1 artinya sangat tidak setuju. Perolehan data hasil 
pemberian angket kemudahan menggunakan media Geogebra akan dianalisis dan diperoleh Persentase Kemudahan Media (PKM) yang dihitung dengan rumus,

$$
P K M=\frac{j u m l a h \text { skor hasil pengumpulan data }}{\text { skor tertinggi } \times \text { jumlah pernyataan } \times \text { jumlah siswa }} \times 100 \%
$$

Selanjutnya, nilai PKM dibandingkan dengan Kriteria yang tertulis dalam tabel 3.

Tabel 3. Kriteria angket kemudahan penggunaan media

\begin{tabular}{cc}
\hline Persentase & Keterangan \\
\hline $0 \% \leq \mathrm{PKM} \leq 25 \%$ & Tidak mudah \\
$25 \%<\mathrm{PKM} \leq 50 \%$ & Kurang mudah \\
$50 \%<\mathrm{PKM} \leq 75 \%$ & Cukup mudah \\
$75 \%<\mathrm{PKM} \leq 100 \%$ & Mudah \\
\hline
\end{tabular}

Adaptasi dari (Sugiyono, 2010).

Perolehan data hasil pemberian angket keminimalan peran guru akan dianalisis dan diperoleh Persentase Keminimalan Guru (PKG) yang dihitung dengan rumus,

$$
P K G=\frac{\text { jumlah skor hasil pengumpulan data }}{\text { skor terting } i \text { iumlah pernyataan }} \times 100 \%
$$

Kemudian, nilai PKG dibandingkan dengan kriteria pada tabel 4, di bawah ini.

Tabel 4. Kriteria angket keminimalan peran guru

\begin{tabular}{cc}
\hline Persentase & Keterangan \\
\hline $0 \% \leq \mathrm{PKG} \leq 25 \%$ & Tidak meminimalkan peran guru \\
$25 \%<\mathrm{PKG} \leq 50 \%$ & Kurang meminimalkan peran guru \\
$50 \%<\mathrm{PKG} \leq 75 \%$ & Cukup meminimalkan peran guru \\
$75 \%<\mathrm{PKG} \leq 100 \%$ & Meminimalkan peran guru \\
\hline
\end{tabular}

Adaptasi dari (Sugiyono, 2010).

Dalam lembar observasi keminimalan peran guru, setiap aspek penilaian diikuti oleh empat skor, yaitu 4 artinya meminimalkan peran guru, 3 artinya cukup meminimalkan peran guru, 2 artinya kurang meminimalkan peran guru, 1 artinya tidak meminimalkan peran guru. Perolehan data hasil lembar observasi keminimalan peran guru akan dianalisis dan diperoleh Persentase Observasi Keminimalan Guru (POKG) yang dihitung dengan rumus.

$$
P O K G=\frac{\text { jumlah skor hasil pengumpulan data }}{\text { skor tertinggi } \times \text { jumlah pernyataan } \times \text { jumlah observer }} \times 100 \%
$$

Nilai POKG yang telah dibagi dengan jumlah pertemuan (rata-rata POKG) dibandingkan dengan kriteria pada tabel 5. 
Tabel 5. Kriteria angket keminimalan peran guru

\begin{tabular}{cc}
\hline Persentase & Keterangan \\
\hline $0 \% \leq$ POKG $\leq 25 \%$ & Tidak meminimalkan peran guru \\
$25 \%<$ POKG $\leq 50 \%$ & Kurang meminimalkan peran guru \\
$50 \%<$ POKG $\leq 75 \%$ & Cukup meminimalkan peran guru \\
$75 \%<$ POKG $\leq 100 \%$ & Meminimalkan peran guru
\end{tabular}

Adaptasi dari (Sugiyono, 2010)

Dengan demikian, Media Geogebra dikatakan praktis jika nilai persentase angket kemudahan penggunaan media Geogebra berada pada kriteria mudah, nilai persentase angket keminimalan peran guru dan hasil observasi keminimalan peran guru berada pada kategori meminimalkan peran guru.

Keefektifan Media Geogebra diperoleh berdasarkan hasil pemberian Tes Prestasi Belajar. Nilai Prestasi Belajar Siswa akan dibandingkan dengan Kriteria Ketuntasan Minimal (KKM) mata pelajaran matematika di SMPN 12 Madiun yaitu siswa dikatakan tuntas dengan nilai minimal 75. Media pembelajaran dikatakan efektif jika Persentase Ketuntasan Klasikal $(\mathrm{PKK}) \geq 75 \%$. Persentase ketuntasan secara klasikal (PKK) dihitung dengan rumus,

$$
P K K=\frac{\text { jumlah siswa tuntas }}{\text { jumlah siswa seluruhnya }} \times 100 \%
$$

\section{Hasil Penelitian dan Pembahasan}

Validasi dari media pembelajaran, perangkat pendukung dan instrumen yang telah dikembangkan melibatkan dua validator yaitu, satu dosen Program Studi Pendidikan Matematika Universitas Katolik Widya Madala Madiun sebagai validator ahli dan satu Guru Matematika SMPN 12 Madiun sebagai validator praktisi. Hasil validasi pertama dari kedua validator menunjukkan bahwa media pembelajaran, perangkat pendukung dan instrumen sangat valid sehingga siap untuk di uji cobakan. Hal ini dikarenakan, media mudah digunakan karena dalam menggunakannya cukup mengikuti perintah pada BKS. Perintah penggunaan media dalam BKS disusun dengan jelas dan dengan langkah yang singkat. Selain itu tampilan Geogebra menarik, rapi dan sesuai dengan konsep garis singgung persekutuan dua lingkaran. Biaya pembuatan media sangat terjangkau karena aplikasi Geogebra dapat diunduh secara gratis sehingga hanya membutuhkan biaya untuk menggunakan internet. Penggunaan bahasa dalam BPG dan BKS jelas dan mudah dipahami. Media, RPP, BKS, dan BPG dibuat saling berhubungan sehingga dalam pemakaiannya tidak membingungkan pengguna. Berdasarkan analisis hasil validasi tersebut, diperoleh bahwa Media Pembelajaran dan Perangkat Pendukung masuk dalam kriteria sangat valid.

Selain itu, berdasarkan hasil uji coba diperoleh nilai PKM $=79,8 \%$. Jika dibandingkan dengan kriteria pada tabel 3, maka Media Pembelajaran termasuk dalam kategori Mudah Digunakan. Hasil penentuan nilai PKG diperoleh $\mathrm{PKG}=81 \%$. Jika dibandingkan dengan kriteria pada tabel 4, diperoleh kesimpulan bahwa Media Pembelajaran termasuk kategori meminimalkan peran guru. Dari proses analisis data Lembar Observasi Keminimalan Peran Guru diperoleh nilai POKG $=76,95 \%$. Jika dibandingkan dengan kriteria pada tabel 5, maka 
Media Pembelajaran termasuk dalam kategori meminimalkan peran guru. Berdasarkan hasil PKM, PKG, dan POKG, maka dapat dikatakan bahwa Media Pembelajaran Geogebra memenuhi kriteria kepraktisan. Dengan kata lain, hasil pengembangan Media Pembelajaran Geogebra praktis. Berdasarkan hasil pelaksanaan Tes Prestasi Belajar, diperoleh nilai PKK = $35 \%$, sehingga nilai PKK $\leq 75 \%$. Hasil PKK ini menunjukkan bahwa Media Geogebra belum efektif. Tampilan Media Pembelajaran Menggunakan Geogebra dapat dilihat pada gambar 2 dan gambar 3 di bawah ini.

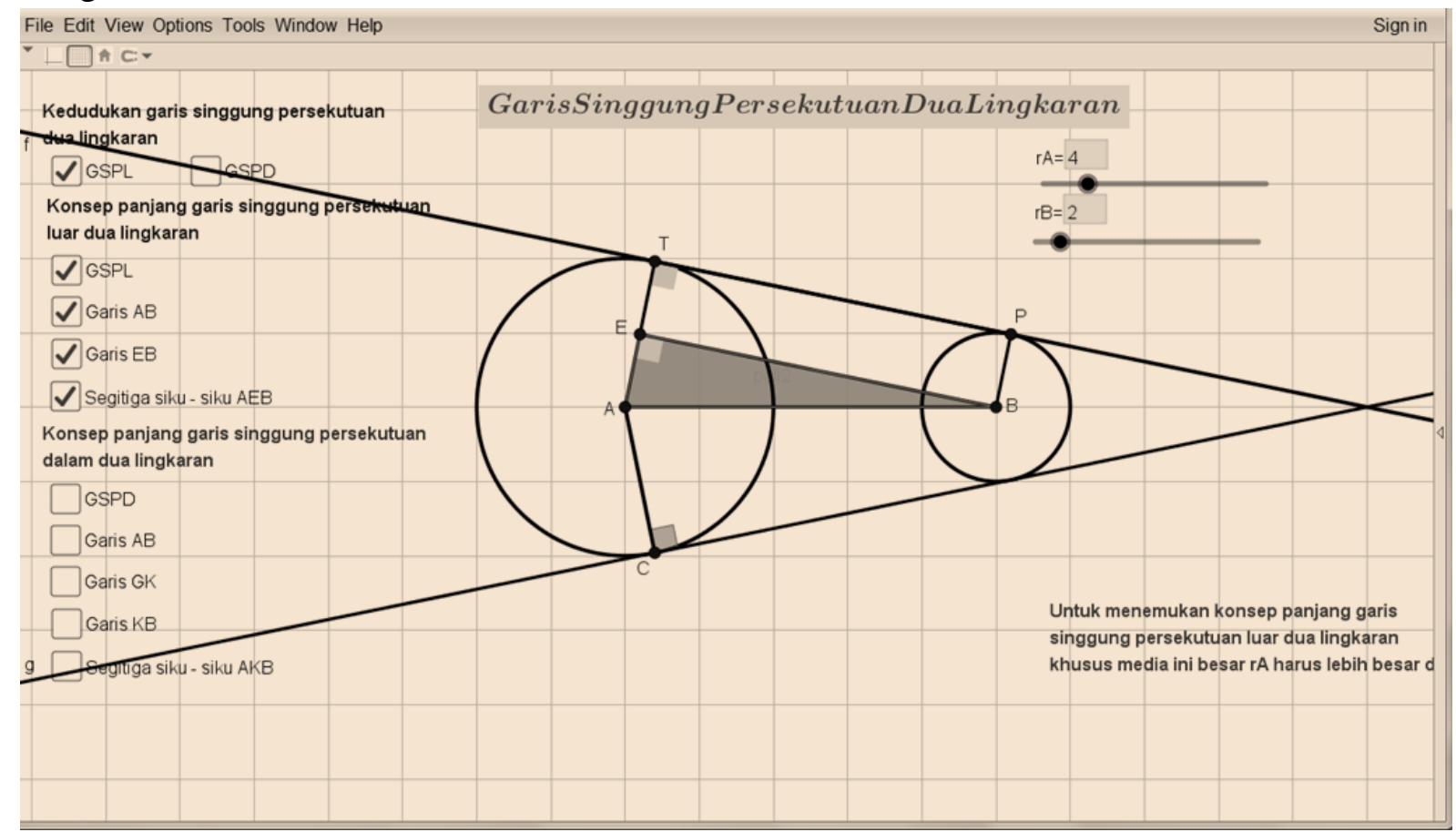

Gambar 2. Garis Singgung Persekutuan Luar dua Lingkaran

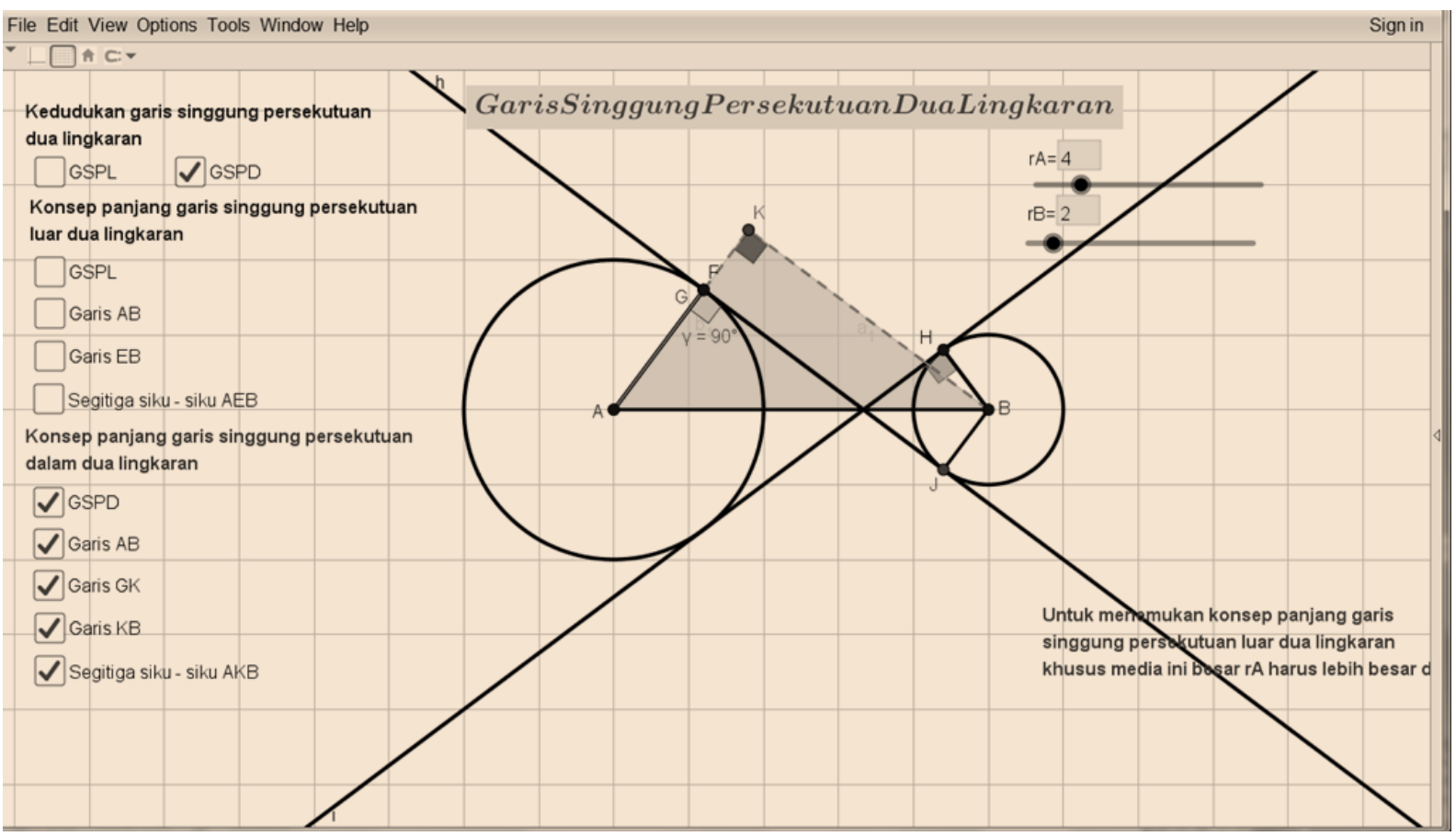

Gambar 3. Garis Singgung Persekutuan Dalam Dua Lingkaran 
Tes hasil belajar dibuat sesuai materi dan kisi-kisi dengan tingkat kemampuan siswa SMP kelas VIII. Selain itu penggunaan bahasa dibuat agar mudah dipahami dan terdapat tambahan gambar pada beberapa soal agar maksud dari soal lebih dipahami oleh siswa. Instrumen seperti angket kemudahan penggunaan media, keminimalan peran guru, dan lembar observasi keminimalan peran guru dibuat dengan bahasa yang mudah dipahami dan sesuai dengan kisi-kisi. Media, perangkat pendukung dan instrumen tidak langsung di gunakan pada uji coba pertama karena terdapat beberapa saran seperti penambahan cara menutup media, perbaikan kalimat pada BKS dan kunci jawaban pada soal latihan maka sebelum uji coba dilakukan revisi kecil terlebih dahulu terhadap media pembelajaran dan perangkat pendukung.

Media, BKS, dan langkah-langkah pembelajaran pada RPP dirancang agar siswa aktif dalam pembelajaran sehingga interaksi guru dan murid berkurang. Jika dilihat pada RPP waktu guru hanya kurang lebih 26 menit dari 80 menit untuk menyelesaikan tugasnya. Sisa waktu 54 menit adalah kegiatan siswa untuk mengerjakan soal dan mengamati. Siswa cukup dapat mengerjakan soal pengamatan. Akan tetapi, ada beberapa soal pengamatan yang dirasa sulit oleh siswa. Pada semua pertemuan, durasi waktu terlama proses pembelajaran terjadi pada tahap pengamatan dan penarikan kesimpulan. Karena hal ini dalam tiga pertemuan kegiatan pembelajaran yang telah direncanakan dalam RPP tidak dapat terselesaikan. Namun hasil POKG mencapai 76,95\% masuk dalam kategori meminimalkan peran guru.

Hasil keefektifan didapat dari tes hasil belajar siswa pada pertemuan ke empat. Tes ini diikuti oleh 32 siswa dengan waktu 80 menit. Soal tes ini terdiri dari 6 soal. Dalam proses pembelajaran, setelah siswa mengamati tiap soal yang berhubungan dengan media guru selalu menampilkan gambar yang benar pada LCD. Selain itu, dalam tiga pertemuan guru selalu memberikan umpan balik setelah siswa mengamati. Dalam hasil tes siswa terdapat 8 siswa yang mencapai nilai di atas 75 . Karena terdapat 8 siswa yang mendapat nilai di atas 75 maka presentase ketuntasan klasikal (PKK) sebesar 35\%, artinya tes hasil belajar ini tidak memenuhi ketuntasan klasikal. Hal ini disebabkan oleh kelemahan media yang dapat membuat siswa kebingungan seperti, jika siswa mengubah ukuran jari-jari lingkaran A lebih kecil dari jari-jari lingkaran B saat mempelajari konsep panjang garis singgung persekutuan luar dua lingkaran maka gambar yang dihasilkan tidak sesuai dengan harapan. Pada sub pokok bahasan kedudukan garis singgung persekutuan dua lingkaran, media hanya dapat menunjukan kedudukan garis singgung dua lingkaran memiliki dua garis singgung persekutuan luar dan satu garis singgung persekutuan dalam jika jumlah kedua jari-jari lingkaran genap. Akan tetapi karena media ini hanya digunakan untuk menunjukkan konsep kedudukan garis singgung persekutuan dua lingkaran maka media ini dirasa cukup oleh peneliti.

Selain itu, dalam pembelajaran di kelas siswa tidak dihadapkan dengan soal-soal latihan. Tentunya hal ini dikarenakan durasi waktu pembelajaran habis digunakan untuk proses pengamatan dan penarikan kesimpulan. Latihan soal dikerjakan di rumah, akan tetapi pada pertemuan selanjutnya tidak ada pembahasan. Dalam penelitian ini seharusnya dilakukan uji coba kedua. Namun penelitian ini tidak dilanjutkan pada uji coba kedua dikarenakan terdapat keterbatasan waktu, yaitu SMPN 12 Madiun telah selesai ulangan akhir 
semester (UAS). Jika mengambil subjek pada kelas VII waktu yang diberikan pihak SMPN 12 Madiun hanya dua hari. Waktu ini tidak mencukupi untuk melakukan uji coba kedua yang membutuhkan waktu empat hari. Jadi hasil dari uji coba ini yaitu media pembelajaran matematika menggunakan Geogebra pada sub pokok bahasan garis singgung persekutuan dua lingkaran dan perangkat pendukung yang telah direvisi berdasarkan hasil uji coba. Pada media construction tools dan bilah masukan pada tampilan media disembunyikan agar dalam penggunaannya nanti, siswa dapat terfokus pada media saja. Untuk mengurangi kelemahan media, pada tampilan media khusus untuk konsep panjang garis singgung persekutuan luar dua lingkaran diberikan syarat bahwa media ini dapat menunjukan langkah menemukan konsep panjang garis singgung persekutuan luar dua lingkaran jika jari-jari lingkaran dengan pusat A lebih kecil dari jari-jari lingkaran dengan pusat B.

\section{Kesimpulan dan Saran}

Berdasarkan hasil pengembangan media pembelajaran matematika menggunakan Geogebra pada sub pokok bahasan garis singgung persekutuan dua lingkaran diperoleh kesimpulan proses pengembangan media pembelajaran matematika berbantu Geogebra pada sub pokok bahasan garis singgung persekutuan dua lingkaran berdasarkan tahap pengembangan Sugiyono yang telah dimodifikasi. Hasil penelitian pengembangan media pembelajaran matematika menggunakan Geogebra pada sub pokok bahasan garis singgung persekutuan dua lingkaran memenuhi kriteria valid, praktis, tetapi belum memenuhi kriteria efektif.

Berdasarkan hasil penelitian ini, terdapat beberapa saran dalam proses pengembangan media pembelajaran Geogebra, yaitu media yang dikembangkan menggunakan Geogebra dapat menjadi alternatif dalam pembelajaran matematika pada sub pokok bahasan garis singgung persekutuan dua lingkaran sehingga dapat membantu meningkatkan kualitas pembelajarana matematika, media yang dikembangkan menggunakan Geogebra dapat digunakan sebagai alat bantu untuk siswa dalam memahami materi garis singgung persekutuan dua lingkaran, geogebra dapat dikembangkan menjadi media pada materi lain yang dapat membantu meningkatkan kualitas pembelajarana matematika, saat menggunakan media Geogebra sehendaknya diperhatikan terlebih dahulu keadaan lab komputer. Jumlah komputer sesuai dengan jumlah siswa dan lab komputer memiliki media pendukung pembelajaran yang lain seperti papan tulis dan LCD, jika media ini digunakan oleh kelas yang memiliki kemampuan kognitif yang rendah maka guru harus lebih aktif berinteraksi pada siswa atau melihat proses pengamatan siswa dalam menemukan konsep dan rumus materi ini, guru harus mengetahui atau bisa menggunakan Geogebra sehingga jika terjadi error guru bisa memperbaiki atau lebih cepatnya guru memiliki cadangan media di flashdisk sehingga jika media error dapat langsung diganti dengan media yang baru, jika melakukan penelitian berkala sebaiknya menggunkan observer yang sama agar hasil penilaiannya lebih akurat.

\section{Daftar Isi}

Arifin, Z. (2012). No Title. Bandung: PT Remaja Rosda Karya.

Dada, R. (2008). Media Pembelajaran. Ciputat: Gaung Persada. 
Hohenwater, M., \& Fuchs, K. (2017). Combination of Dynamic Geometry, Algebra, and Calculus in The Software System Geogebra. Retrieved January 4, 1BC, from https://archive.geogebra.org/static/publications/pecs_2004.pdf

Indahsari, I. N. (2013). Perancangan Perangkat Pembelajaran Matematika Berbantuan Geogebra pada Sub Pokok Bahasan Nilai-nilai Stasioner di Kelas XI IPA dengan Pendekatan Klasikal. Madiun.

Kristanto, V. H. (2011). Diktat Mata Kuliah Profesi Kependidikan. Madiun: Universitas Katolik Widya Mandala Madiun.

Rusman. (2012). Belajar dan Pembelajaran Berbasis Komputer. Bandung: Alfabeta.

Sugiyono. (2010). Metode Penelitian Pendidikan. Bandung: Alfabeta.

Tjeerd, P., \& Nienke, N. (2010). An Intoduction to Educational Design Research. Netherland: SLO. 